\title{
Basidiospore and Protoplast Regeneration from Raised Fruiting Bodies of Pathogenic Ganoderma boninense
}

\author{
NISHA THOPLA GOVENDER ${ }^{1 *}$, MAZIAH MAHMOOD ${ }^{1,3}$, IDRIS ABU SEMAN $^{4}$ \\ and WONG MUI-YUN ${ }^{1,2 *}$ \\ ${ }^{1}$ Institute of Tropical Agriculture, Universiti Putra Malaysia, Selangor D.E., Malaysia \\ ${ }^{2}$ Department of Plant Protection, Faculty of Agriculture, Universiti Putra Malaysia, Selangor D.E., Malaysia \\ ${ }^{3}$ Department of Biochemistry and Biomolecular Sciences, Faculty of Biotechnology, \\ Universiti Putra Malaysia, Selangor D.E., Malaysia \\ ${ }^{4}$ Malaysian Palm Oil Board (MPOB), Persiaran Institusi, Bandar Baru Bangi, Selangor D.E., Malaysia
}

Submitted 14 November 2015, revised 29 January 2016, accepted 2 February 2016

Abstract

Ganoderma boninense, a phytopathogenic white rot fungus had sought minimal genetic characterizations despite huge biotechnological potentials. Thus, efficient collection of fruiting body, basidiospore and protoplast of G. boninense is described. Matured basidiocarp raised under the glasshouse conditions yielded a total of $8.3 \times 10^{4}$ basidiospores $/ \mathrm{ml}$ using the low speed centrifugation technique. Mycelium aged 3-day-old treated under an incubation period of $3 \mathrm{~h}$ in lysing enzyme from Trichoderma harzianum $(10 \mathrm{mg} / \mathrm{ml})$ suspended in osmotic stabilizer $(0.6 \mathrm{M}$ potassium chloride and $20 \mathrm{mM}$ dipotassium phosphate buffer) yielded the highest number of viable protoplasts $\left(8.9 \times 10^{6}\right.$ single colonies) among all possible combinations tested (regeneration media, age of mycelium, osmotic stabilizer, digestive enzyme and incubation period).

Key words: basidiocarp, basidiospore, incubation, lytic enzyme

Ganoderma boninense, a phytopathogenic fungus causes basal stem rot (BSR) disease in oil palm and thus, is deemed a prime candidate for genetic, molecular and transformation studies. Very little studies have documented the biology and molecular genetics of G. boninense (Shi et al., 2012). The studies of fungal functional genomics are becoming more prevalent with the availability of fully sequenced genomes (Michielse etal., 2005; Wang et al., 2010). Currently, genome sequencing of G. boninense is underway (Malaysian Palm Oil Board) (http://www.genomesonline.org), hence an efficient protoplast and basidiospore production system would prepare the species to functional studies related to BSR disease. The objective of this study is to develop a highly efficient method for protoplast regeneration from basidiospores collected from raised fruiting bodies under the glasshouse conditions. A morphological description of the ideal fruiting structure which gives the best sporulating activity was determined. In order to determine the optimal condition desired for G. boninense protoplast isolation and regeneration, factors such as age of mycelia, type of osmoticum, lytic enzymes and enzyme incubation period were investigated.

The G.boninense strain $\mathrm{T} 10$ was provided by Applied Agricultural Resources, Sdn Bhd (AAR), Sungai Buloh. The strain was verified positive G. boninense as indicated by visible brown ring formation under the Ganoderma Selective Medium (GSM) amendment. The fungus was maintained on maltose extract agar (MEA; Merck) prior to usage. A rubber wood block (RWB) measuring $6 \times 6 \times 6 \mathrm{~cm}$ was soaked in distilled water overnight prior to sterilization at $121^{\circ} \mathrm{C}$ for $30 \mathrm{~min}$. The RWB was supplemented with $100 \mathrm{ml}$ of molten MEA, swirled to uniform distribution. Three pieces of mycelia cubes $(1 \times 1 \mathrm{~cm})$ were inoculated at random sides of the RWB, thereafter incubated in darkness at room temperature for six weeks. Sterilized soil mixture prepared at 3:2:1 topsoil/peat/sand was filled in flower pot $(40 \times 30 \mathrm{~cm})$ covering 3:4 parts of the total volume. The RWB inoculum with an attached oil palm seedling (3-month-old) on its side was carefully planted into soil, at about $1-2 \mathrm{~cm}$ from the soil surface, positioned vertically to expose the adaxial axis

\footnotetext{
* Corresponding author: N.T. Govender, Institute of Tropical Agriculture, Universiti Putra Malaysia, Serdang, Selangor D.E., Malaysia; e-mail: nish_277@yahoo.com and W. Mui-Yun, Institute of Tropical Agriculture, Universiti Putra Malaysia, Selangor D.E., Malaysia; e-mail: muiyun@upm.edu.my
} 
of the RWB to the open air. Soil was maintained moist under regular watering. Development of the G. boninense fruiting body was monitored for a period of five months throughout a hot and wet climate. The resultant fruiting body harvested at varying maturity periods were subjected to basidiospore isolation. Fruiting body was immersed into 10\% Chlorox solution for $30 \mathrm{~min}$ followed by $70 \%$ ethanol for $10 \mathrm{~min}$. A sterile razor blade was used to cut the hymenium region into small cubes of $5 \times 5 \mathrm{~mm}$ each. The excised cubes $(0.5 \mathrm{~g})$ were dropped into $100 \mathrm{ml}$ of deionized water. The mixture was subjected to shaking for $30 \mathrm{~min}$ at $85 \times g$ at room temperature. The mixture was filtered using a small amount of glass wool fitted into a glass tunnel. The filtrate was collected as aliquots of $2 \mathrm{ml}$. The basidiospore suspension was subjected to low speed centrifugation at $1000 \times g$ for $1 \mathrm{~min}$. The concentration of the basidiospore suspension harvested from the supernatant region was determined using a haemocytometer. Direct inoculation onto PDA (39 g/l), MEA (48 g/l) and Ganoderma Complete Medium (GCM) plates using a sterile cotton swab was performed to evaluate presence/ absence of contaminants. The GCM medium was prepare following Choi et al. (1987) with slight modifications; glucose $30 \mathrm{~g} / \mathrm{l}$, sucrose $20 \mathrm{~g} / \mathrm{l}, \mathrm{MgSO}_{4} \cdot 7 \mathrm{H}_{2} \mathrm{O}$ $0.5 \mathrm{~g} / \mathrm{l}, \mathrm{K}_{2} \mathrm{HPO}_{4} 1 \mathrm{~g} / \mathrm{l}, \mathrm{KH}_{2} \mathrm{PO}_{4} 0.5 \mathrm{~g} / \mathrm{l}$, yeast extract agar $10 \mathrm{~g} / \mathrm{l}$, casein hydrolysate $5 \mathrm{~g} / \mathrm{l}$. Basidiospore suspensions $\left(10^{5}-10^{6} \mathrm{ml}^{-1}\right)$ were subjected to serial dilution to yield 3-5 mycelial colonies in each $100 \mathrm{ml} \mathrm{PD-broth.}$ Mycelia were harvested from the liquid culture at day 3,4 and 5 to investigate the effect of age on protoplast release. The osmotic stabilizer was prepared to constitute either sucrose or potassium chloride at $0.6 \mathrm{M}$ in presence of $20 \mathrm{mM}$ dipotassium hydrogen phosphate. Lytic enzyme fixed at $10 \mathrm{mg} / \mathrm{ml}$, was diluted into the osmotic stabilizer. Commercial lytic enzymes utilized were $\beta$-(1-3) D-glucanase, lysing enzyme from Trichoderma harzianum and Driselase (Sigma-Adrich, USA). The mixture containing mycelia and osmotic stabilizer $\left(1: 5\right.$ weight/vol) was incubated in a water bath at $30^{\circ} \mathrm{C}$ for $5 \mathrm{~h}$. The production of protoplast was examined at 1 , 3 and $5 \mathrm{~h}$ throughout the incubation period. The resultant protoplasts were spread onto regeneration media consist of PDA and GCM, supplemented with $0.6 \mathrm{M}$ sucrose and $20 \mathrm{mM}$ phosphate buffer. The number of viable protoplasts released was observed as the number of single colonies (mycelial pellets). The number of colonies appeared on the surface of the regeneration plates at day 10 after inoculation was recorded.

At week-3 after the artificial set-up for development of G. boninense fruiting bodies, visible hyphal knots were observed on the surface of the potting media, suggesting the initiation of photomorphogenesis. The rates of differentiation among the pots were highly variable. This in turn suggests presence of individual niches among the pots (Kamada, 2002) affecting polarisation of hyphae into fruiting structure. Fruiting body initials were observed protruding out from the surface of RWB at week-4 onwards. The sporophore was about $1 \mathrm{~cm}$, white in colour, and round in shape with no visible hymenium (Fig. 1A). Next, the single-structured sporophore budded to form two of more structures round in shape with white surface, affixed on a deep red-brownish coloured stunted stipe (Fig. 1B). At this stage, visible hymenium was observed on the underside (white surface) with poor distribution. The sporophore differentiates into primordium/basidiocarp with characteristic cap and stipe formation. The cap takes up a bracket shape with reddish to orange colour on its outer surface, white coloured on its terminal region and confluent formation of visible hymenium on its underside (Fig. 1C). As the basidiocarp continues to develop, the cap showed deep red colouration entirely with orange coloration at the sub-terminal region and white coloration at the terminal region of the bracketed shape. On the underside, even distribution of visible hymenium was observed (Fig. 1D). Finally, the bracketed shape showed a completely deep red coloration and shrunk over time. The underside was found covered with visible hymenium (Fig. 1E).

In order to determine the effect of fruiting body's maturity on production of basidiospores, five distinct sizes of fruiting bodies were harvested. Fruiting bodies with a basidiocarp diameter in a range from $4-6 \mathrm{~cm}$ (Fig. 1D) showed highest rate of basidiospore production with a yield of $83 \times 10^{3} \mathrm{ml}^{-1}$ mycelial pellets. Sporophore (less than $1 \mathrm{~cm}$ ) with no visible formation of hymenium failed to sporulate even in the presence of a distinct fruiting structure. It appeared that the best way to determine a sporulating fruiting body would be to harvest fruiting bodies with a well-developed basidiocarp (diameter $>3 \mathrm{~cm}$ ), visible hymenium and brightly coloured (Fig. 1C-1E). Sporophore with invisible hymenium showed poor rate of sporulation in comparison to well-developed basidiocarp, which showed visible hymenium (Fig. 1F) and large pore size. Basidiocarp with a pale colouration showed poor sporulation activity with a total of $35 \times 10^{3} \mathrm{ml}^{-1}$ mycelia pellets, indicates senescence period of the fungus life cycle (Fig. 1E). Amongst the regeneration media selected, PDA showed the best regeneration capability followed by GCM (Fig. 2A) whilst MEA (data not shown) showed poor ability to regenerate basidiospores. This protocol recruited a combination of both forcible spore discharge method and the density gradient method which are widely employed for basidiomycetes basidiospore isolation (An, 2005). Hymenium was selectively harvested for basidiospore isolation as this region enclosed within the hard fruiting structure, renders a highly sterile environment. The tissues were dis- 

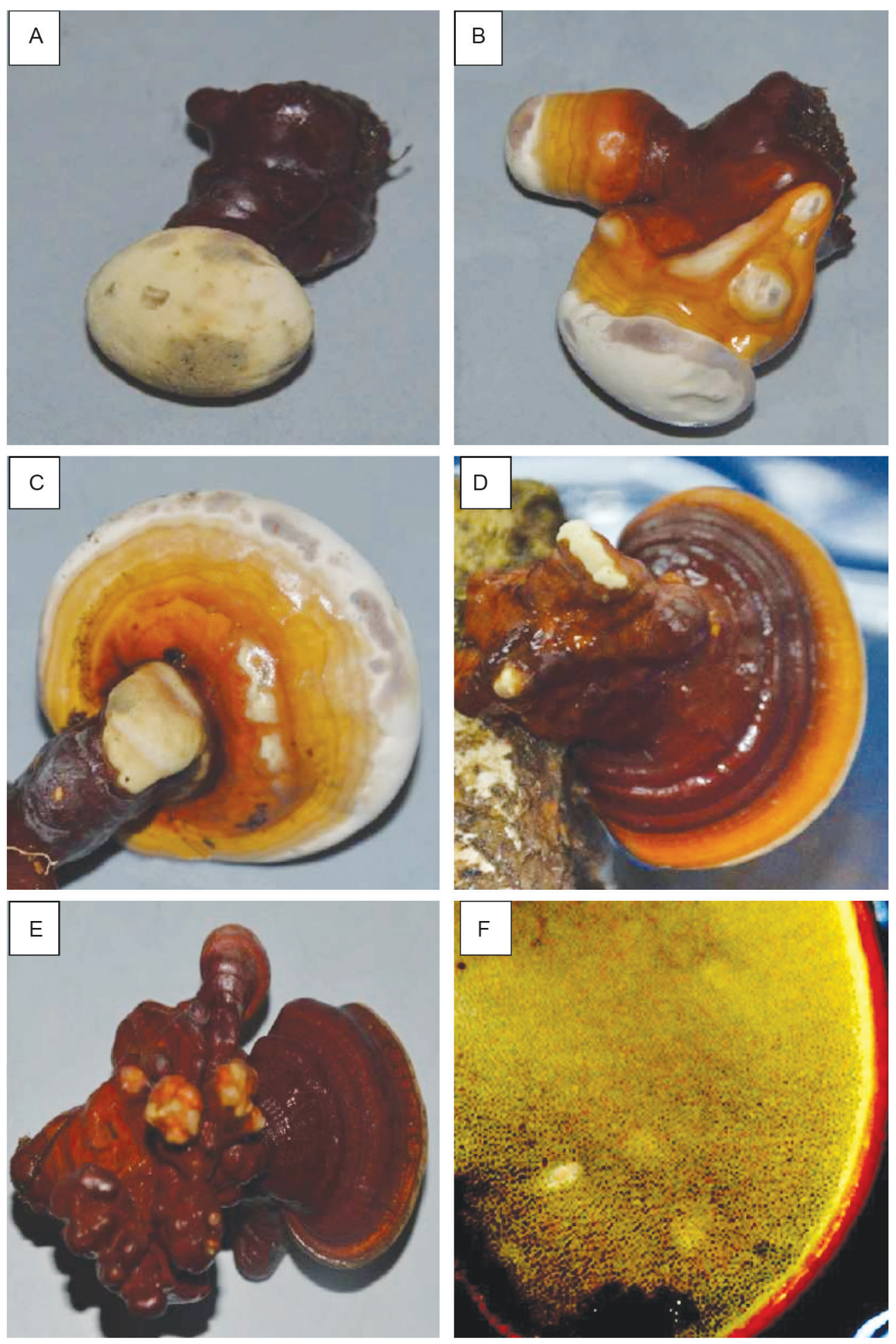

Fig. 1. Fruiting bodies of G. boninense harvested at different developmental stages. A) Sporophore; B) Budding sporophores; C) Basidiocarp; D) Matured basidiocarp; E) Senescent basidiocarp;

F) Hymenium observed at underside of matured basidiocarp.

sected into small pieces to increase the surface required to allow the adhering basidiospores to escape into liquid solution during the shaking process. Ethanol based cleaning facilitated removal of coloured compound present on the fruiting structure. A prolonged pre-treatment of basidiospores under $10 \%$ Chlorox solution explained the resistant nature of the G. boni- nense basidiospores, which showed no adverse effect over the regeneration process. Centrifugation at relatively low speed enables large particles (contaminants) to be easily separated from basidiospores which are much smaller in size, yielding a virtually contaminant free basidiospore suspension as evident during basidiospore regeneration into mycelial colonies (Fig. 2A). 

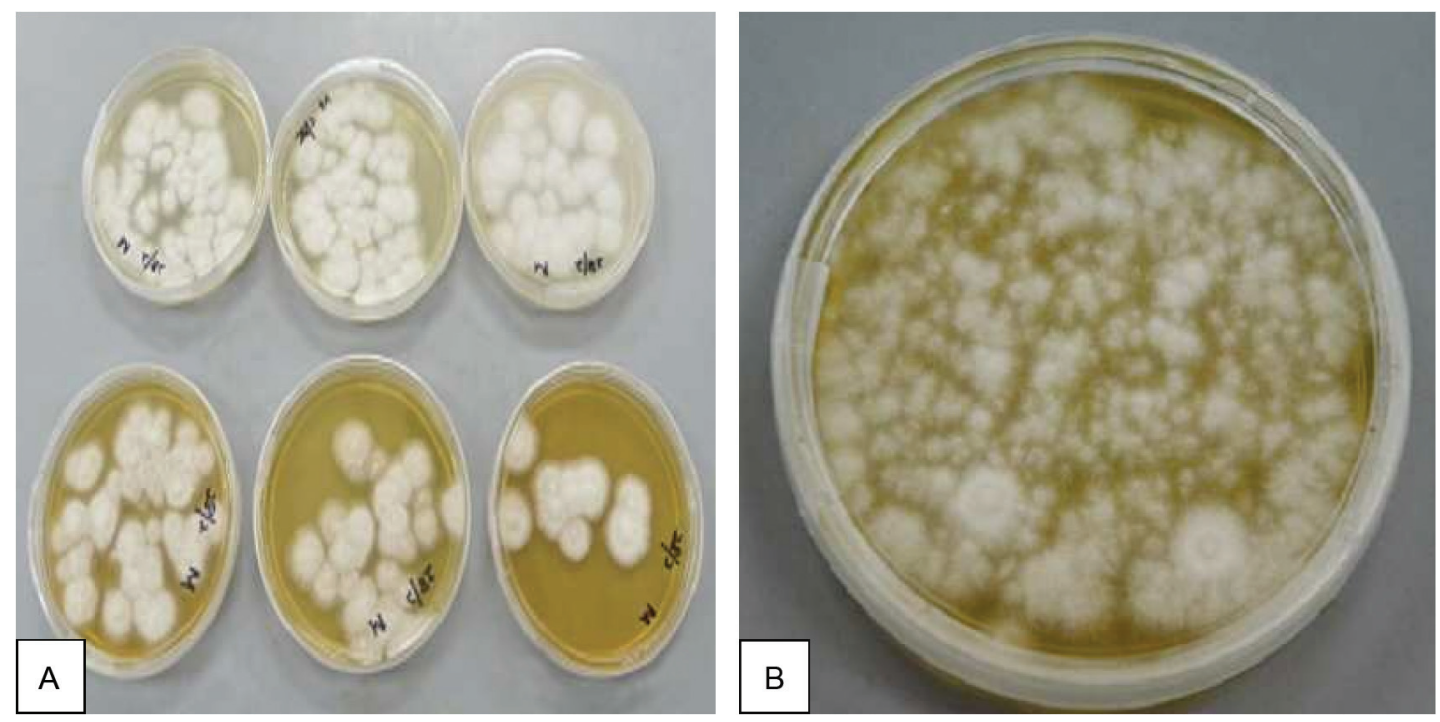

Fig. 2. A) Basidiospores (G. boninense) regenerated on PDA (above) and GCM (below) in absence of antibiotics supplementation on day 14 after inoculation.

B) Single colonies regenerated on PDA suspended in phosphate buffer and $0.6 \mathrm{M}$ sucrose from protoplast suspension after $3 \mathrm{~h}$ enzymatic digestion using $10 \mathrm{mg} / \mathrm{ml}$ lytic enzyme from Trichoderma harzianum and $0.6 \mathrm{M} \mathrm{KCl}$ as osmotic stabilizer at day 10 after inoculation.

The number of protoplasts regenerated under all possible combinations tested in this study ranged from $2-89 \times 10^{5}$ single colonies $\mathrm{ml}^{-1}$ (Table I). To assign the best possible combination for efficient protoplast regeneration, treatments with mycelial colonies ranging at $10^{6}-10^{5}$ were designated as high, $10^{4}-10^{2}$ being moderate and below $10^{2}$ as poor yield. Each treatment was evaluated using mycelium at different ages subjected to varying lytic enzymes, osmotic stabilizers and growth media under selected incubation periods. Mycelia were harvested at day 3, 4 and 5 to identify optimal age for protoplast production. Day 1 and 2 were not utilized since no visible mycelium mass were observed. Mycelia aged 3-day-old produced the highest viable protoplast yield $\left(89 \times 10^{5}\right.$ single colonies $\left.\mathrm{ml}^{-1}\right)$ on PDA when treated with lytic enzyme from T.harzianum at an incubation period of $3 \mathrm{~h}$ (Fig. 2B) followed by mycelia aged 4 -day-old $\left(14 \times 10^{3}\right.$ single colonies $\left.\mathrm{ml}^{-1}\right)$ under a similar treatment conditions. Moderate protoplast yield was observed on mycelia aged 5-day-old $\left(35 \times 10^{2}\right.$ single colonies $\left.\mathrm{ml}^{-1}\right)$ with peaked protoplast yield at an incubation period of $5 \mathrm{~h}$. The protoplast production observed during $3 \mathrm{~h}$ incubation period was relatively moderate to high for 3 and 4 -day-old mycelia $\left(3 \times 10^{2}-78 \times 10^{5}\right.$ single colonies $\left.\mathrm{ml}^{-1}\right)$. In contrast, the 5 -day-old mycelia $\left(5 \times 10^{2}-84 \times 10^{3}\right.$ single colonies $\mathrm{ml}^{-1}$ ) recruited a prolonged incubation period, $5 \mathrm{~h}$ for an optimal digestion of a more intricate cell wall structure. The structure of fungal cell wall remodels throughout its growth. Newly synthesized cell walls are generally more thin and smooth in comparison to older tissues which comprise of primary and secondary layers which are heavily deposited with amorphous matrix materials (Annamalai and Lalithakumari, 1991; Lalithakumari, 1996).

Incubation period was observed as limiting factor throughout the three intervals. Mycelial age was found to affect the protoplast productions. Generally, a similar trend was observed on the incubation period tested among all treatment combinations. Poor to moderate protoplast production was observed in the first hour $\left(2-76 \times 10^{2}\right.$ single colonies $\left.\mathrm{ml}^{-1}\right)$, however, protoplast yield increased rapidly and peaked at $3 \mathrm{~h}\left(8-89 \times 10^{5}\right.$ single colonies $\left.\mathrm{ml}^{-1}\right)$. At $5 \mathrm{~h}$, protoplast yield declined $\left(2 \times 10^{2}-84 \times 10^{3}\right.$ single colonies $\left.\mathrm{ml}^{-1}\right)$ probably indicates the proteolytic activity of the pre-existing protoplast which affects the production of newly-formed protoplast (Robinson and Deacon, 2001). Enzyme incubation period of $3 \mathrm{~h}$ was found effective for maximal protoplast production from G. boninense mycelia of 3 -day-old $\left(89 \times 10^{5}\right.$ single colonies $\left.\mathrm{ml}^{-1}\right)$ and 4 -day-old $\left(14 \times 10^{3}\right.$ single colonies $\left.\mathrm{ml}^{-1}\right)$. In basidiomycetes, the fungal cell wall constitutes $\alpha$-1-3-glucan, xylose and hemicelluloses (Adams, 2004). Three different commercial lytic enzymes from different origin exhibited variable enzymatic enzyme-cell wall digestibility of G.boninense. The lytic enzyme from T.harzianum contains $\beta$-glucanase, chitinase, cellulase and protease activities. This preparation has been predominantly employed for protoplasing filamentous fungi (Liu et al., 2010; Rivera et al., 2014), basidiomycetes (Shi et al., 2012) and yeast (Kelly and Nurse, 2011). Driselase originates from basidiomycetes sp. containing laminerase, xylanase and cellulase activities. It has also shown efficient digestibility on other fungal species (Souza et al., 2014). The $\beta$-(1-3) D-glucanase 
Table I

Effect of incubation time and lytic enzymes $(10 \mathrm{mg} / \mathrm{ml})$ on protoplast yield/ml from G. boninense mycelia treated in different osmotic stabilizer and regeneration media

\begin{tabular}{|c|c|c|c|c|c|c|}
\hline \multirow{2}{*}{ Mycelial age } & \multirow{2}{*}{$\begin{array}{l}\text { Lytic enzyme/ } \\
\text { Source }\end{array}$} & \multirow{2}{*}{ Media } & \multirow{2}{*}{$\begin{array}{l}\text { Osmotic } \\
\text { stabilizer }\end{array}$} & \multicolumn{3}{|c|}{ Protoplast regenerated as single colonies $/ \mathrm{ml}$} \\
\hline & & & & $1 \mathrm{~h}$ & $3 \mathrm{~h}$ & $5 \mathrm{~h}$ \\
\hline \multirow[t]{12}{*}{ 3-day culture } & \multirow[t]{4}{*}{ Driselase } & \multirow[t]{2}{*}{ PDA } & Sucrose & 50 & $56 \times 10^{5}$ & $23 \times 10^{2}$ \\
\hline & & & $\mathrm{KCl}$ & 80 & $78 \times 10^{5}$ & $40 \times 10^{2}$ \\
\hline & & \multirow[t]{2}{*}{ GCM } & Sucrose & 40 & $34 \times 10^{5}$ & $11 \times 10^{2}$ \\
\hline & & & $\mathrm{KCl}$ & 20 & $46 \times 10^{5}$ & $7 \times 10^{2}$ \\
\hline & \multirow[t]{4}{*}{$\beta$-(1-3) D-glucanase } & \multirow[t]{2}{*}{ PDA } & Sucrose & $21 \times 10^{2}$ & $22 \times 10^{4}$ & $3 \times 10^{2}$ \\
\hline & & & $\mathrm{KCl}$ & $34 \times 10^{2}$ & $34 \times 10^{4}$ & $4 \times 10^{2}$ \\
\hline & & \multirow[t]{2}{*}{ GCM } & Sucrose & $18 \times 10^{2}$ & $17 \times 10^{4}$ & $2 \times 10^{2}$ \\
\hline & & & $\mathrm{KCl}$ & $26 \times 10^{2}$ & $17 \times 10^{4}$ & $5 \times 10^{2}$ \\
\hline & \multirow[t]{4}{*}{ T. harzianum } & \multirow[t]{2}{*}{ PDA } & Sucrose & $3 \times 10^{2}$ & $72 \times 10^{5}$ & $11 \times 10^{2}$ \\
\hline & & & $\mathrm{KCl}$ & $13 \times 10^{2}$ & $89 \times 10^{5}$ & $28 \times 10^{2}$ \\
\hline & & \multirow[t]{2}{*}{ GCM } & Sucrose & $10 \times 10^{2}$ & $65 \times 10^{5}$ & $14 \times 10^{2}$ \\
\hline & & & $\mathrm{KCl}$ & $15 \times 10^{2}$ & $69 \times 10^{5}$ & $21 \times 10^{2}$ \\
\hline \multirow{12}{*}{ 4-day culture } & \multirow[t]{4}{*}{ Driselase } & \multirow[t]{2}{*}{ PDA } & Sucrose & $81 \times 10$ & $17 \times 10^{2}$ & $17 \times 10^{2}$ \\
\hline & & & $\mathrm{KCl}$ & $74 \times 10$ & $34 \times 10^{2}$ & $21 \times 10^{2}$ \\
\hline & & \multirow[t]{2}{*}{ GCM } & Sucrose & $68 \times 10$ & $18 \times 10^{2}$ & $34 \times 10^{2}$ \\
\hline & & & $\mathrm{KCl}$ & $76 \times 10$ & $26 \times 10^{2}$ & $18 \times 10^{2}$ \\
\hline & \multirow[t]{4}{*}{$\beta$-(1-3) D-glucanase } & \multirow[t]{2}{*}{ PDA } & Sucrose & $23 \times 10$ & $3 \times 10^{2}$ & $26 \times 10^{2}$ \\
\hline & & & $\mathrm{KCl}$ & $17 \times 10$ & $13 \times 10^{2}$ & $3 \times 10^{2}$ \\
\hline & & \multirow[t]{2}{*}{ GCM } & Sucrose & $9 \times 10$ & $10 \times 10^{2}$ & $13 \times 10^{2}$ \\
\hline & & & $\mathrm{KCl}$ & $15 \times 10$ & $15 \times 10^{2}$ & $10 \times 10^{2}$ \\
\hline & \multirow[t]{4}{*}{ T. harzianum } & \multirow[t]{2}{*}{ PDA } & Sucrose & $58 \times 10^{2}$ & $11 \times 10^{3}$ & $15 \times 10^{2}$ \\
\hline & & & $\mathrm{KCl}$ & $76 \times 10^{2}$ & $14 \times 10^{3}$ & $16 \times 10^{2}$ \\
\hline & & \multirow[t]{2}{*}{ GCM } & Sucrose & $67 \times 10^{2}$ & $12 \times 10^{3}$ & $17 \times 10^{2}$ \\
\hline & & & $\mathrm{KCl}$ & $65 \times 10^{2}$ & $12 \times 10^{3}$ & $15 \times 10^{2}$ \\
\hline \multirow[t]{12}{*}{ 5-day culture } & \multirow[t]{4}{*}{ Driselase } & PDA & Sucrose & 23 & 93 & $8 \times 10^{2}$ \\
\hline & & & $\mathrm{KCl}$ & 17 & 88 & $6 \times 10^{2}$ \\
\hline & & GCM & Sucrose & 18 & 45 & $7 \times 10^{2}$ \\
\hline & & & $\mathrm{KCl}$ & 12 & 82 & $5 \times 10^{2}$ \\
\hline & $\beta$-(1-3) D-glucanase & $\mathrm{PDA}$ & Sucrose & 5 & 9 & $13 \times 10^{2}$ \\
\hline & & & $\mathrm{KCl}$ & 6 & 2 & $19 \times 10^{2}$ \\
\hline & & GCM & Sucrose & 2 & 8 & $27 \times 10^{2}$ \\
\hline & & & $\mathrm{KCl}$ & 3 & 8 & $35 \times 10^{2}$ \\
\hline & T. harzianum & PDA & Sucrose & 45 & $23 \times 10^{2}$ & $76 \times 10^{3}$ \\
\hline & & & $\mathrm{KCl}$ & 46 & $35 \times 10^{2}$ & $84 \times 10^{3}$ \\
\hline & & GCM & Sucrose & 38 & $11 \times 10^{2}$ & $57 \times 10^{3}$ \\
\hline & & & $\mathrm{KCl}$ & 42 & $29 \times 10^{2}$ & $63 \times 10^{3}$ \\
\hline
\end{tabular}

was utilized to study the effect of single enzyme treatment over the G. boninense cell wall digestion. The lytic enzyme from T. harzianum showed the best efficiency $\left(89 \times 10^{5}\right.$ single colonies $\left.\mathrm{ml}^{-1}\right)$ for G. boninense protoplast production indicated $\beta-1,3$ glucanase, protease and chitinase are synergistically effective in degradation of $G$. boninense cell wall. The finding complements with the fungi polysaccharides cell wall compositions which constitute mainly cellulose and chitin (Yan et al., 2004; Wang et al., 2010; Souza et al., 2014). This is followed by Driselase $\left(78 \times 10^{5}\right.$ single colonies $\left.\mathrm{ml}^{-1}\right)$, which showed better enzyme activity in comparison to $\beta$-(1-3) D-glucanase $\left(34 \times 10^{4}\right.$ single colonies $\left.\mathrm{ml}^{-1}\right)$. Driselase acted selectively on both xylan hemicellulose and glucose polymers which constitute G. boninense cell wall (Mendoza, 1992). The results demonstrated stable integration of several compositions in fungi cell wall, thus, the usage of only one lytic enzyme is not 
favourable for protoplast release of G. boninense. Protoplasts release was fairly high on both potassium chloride and sucrose supplemented osmotic stabilizers under most treatments. Potassium chloride treated protoplasts regenerated $\left(3-89 \times 10^{5}\right.$ single colonies $\left.\mathrm{ml}^{-1}\right)$ at a higher rate than sucrose treated protoplasts $\left(2-72 \times 10^{5}\right.$ single colonies $\left.\mathrm{ml}^{-1}\right)$ under all treatment combinations (Table I). The findings, however, contradicted with protoplast production from G. lucidum which demonstrated sucrose as optimal osmotic stabilizer (Choi et al., 1987). Osmotic stabilizer composed of inorganic sugar $\mathrm{KCl}$ was consistently more efficient than the organic sugar, sucrose. PDA was the most suitable regeneration medium for protoplast as number of single colonies regenerated in PDA $\left(5-89 \times 10^{5}\right.$ single colonies $\mathrm{ml}^{-1}$ ) was consistently higher than GCM $\left(2-69 \times 10^{5}\right.$ single colonies $\left.\mathrm{ml}^{-1}\right)$ in all treatment combinations (Table I). Medium used for regeneration of protoplast was consistent with basidiospore regeneration which evident PDA as the highly efficient medium for reversion into filamentous morphology.

In conclusion, usage of inorganic sugar for lysing procedure and organic sugar for selection facilitates isolation and regeneration of G. boninense protoplast respectively. Next, raised fruiting body for collection of actively growing mycelia (exponential phase) is a fundamental key attribute to protoplast regeneration procedure. Our study is the first to demonstrate isolation of contaminant free G. boninense basidiospore and its subsequent regeneration into mycelium, which was directly used for protoplast regeneration. The method described here detailing on the protoplast and basidiospore preparation would render G. boninense strain receptive to advanced technologies which ultimately creates avenue towards high-throughput researches.

\section{Funding}

This work was supported by the Fundamental Research Grant Scheme (Vot Num. 552425), Universiti Putra Malaysia.

\section{Acknowledgement \\ The first author would like to thank Ministry of Higher Educa- tion Malaysia for MyBrain 15 postgraduate scholarship.}

\section{Literature}

Adams D.J. 2004. Fungal cell wall chitinases and glucanases. Microbiology 150: 2029-2035.

An Z. 2005. Handbook of Industrial Mycology. CRC Press: Marcel Dekker New York.

Annamalai P. and D. Lalithakumari. 1991. Isolation and regeneration of protoplasts from mycelium of Dreschlera oryzae. J. Plant Dis. Prot. 98: 197-204.

Choi S.H., B.K. Kim, H.W. Kim, J.H. Kwak, E.C. Choi, Y.C. Kim, Y.B. Yoo and Y.H. Park. 1987. Studies on protoplast formation and regeneration of Ganoderma lucidum. Arch. Pharm. Res. 10(3): 158-164.

Kamada T. 2002. Molecular genetics of sexual development in the mushroom Coprinus cinereus. Bioessay 24: 449-459.

Kelly F.D. and Nurse P. 2011. de Novo growth zone formation from fission yeast spheroplasts. PLoS One 6: e27977.

Lalithakumari D. 1996. Protoplasts-A biotechnological tool for plant pathological studies. Ind. Phytopath. 49: 199-212.

Liu T.H., M.J. Lin and W.H. Ko. 2010. Factors affecting protoplast formation by Rhizoctonia solani. New Biotechnology, DOI:10.1016/j. nbt.2009.08.009.

Mendoza C.G. 1992. Cell wall structure and protoplast reversion in basidiomycete. World J. Microbiol. Biotechnol. 8(Suppl. 1).

Michielse C.B., M. Arentshorst, A.F.J. Ram and C.A.M.J.J. van den Hondel. 2005. Agrobacterium- mediated transformation leads to improved gene replacement efficiency in Aspergillus awamori. Fungal Genet. Biol. 42: 9-19.

Rivera A.L., D. Magana-Ortiz and M. Gomez-Lim. 2014. Physical methods for genetic transformation of fungi and yeast. Phs Life Rev. 11: 184-203.

Robinson H.L. and J.W. Deacon. 2001. Protoplast preparation and transient transformation of Rhizoctani solani. Mycol. Res.105: 1295-1303.

Souza A.G.C., S. Herrero, L.A. Mafia and M.E. Daub. 2014. Methods for Cercospora coffeicola protoplast isolation and genetic transformation with green fluorescent protein. Euro. J. Plant Pathol. 139: 241-244.

Shi L., X. Fang, M. Li, D. Mu, A. Ren and M. Zhao. 2012. Development of simple and efficient transformation system for the basidiomycetous medicinal fungus Ganoderma lucidum. World J. Microbiol. Biotechnol. 28: 283-291.

Wang M., S. Liu, Y. Li, R. Xu, C. Lu and Y. Shen. 2010. Protoplast mutation and genome shuffling induce the endophytic fungus tubercularia sp. TF5 to produce new compounds. Curr. Microbiol. 61: 254-260

Yan P.S., J.H. Jiang and W.S. Cui. 2004. Characterization of protoplast prepared from the edible fungus, Stropharia rugosa-annulata. World J. Microbiol. Biotechnol. 20: 173-177. 